\title{
Making the best of lousy circumstances: the impact of salmon louse Lepeophtheirus salmonis on depth preference of sea trout Salmo trutta
}

\author{
Agnes Marie Mohn ${ }^{1,2, *}$, Knut Wiik Vollset ${ }^{3}$, Egil Karlsbakk ${ }^{1}$ \\ ${ }^{1}$ Department of Biological Sciences, University of Bergen, Thormøhlensgate 53A, 5006 Bergen, Norway \\ ${ }^{2}$ Institute of Marine Research, Hjalmar Johansens gate 14, 9007 Tromsø, Norway \\ ${ }^{3}$ NORCE, LFI - Freshwater Biology, Nygårdsporten 112, 5006 Bergen, Norway
}

\begin{abstract}
Sea trout are known for seeking out sources of freshwater to rid themselves of salmon lice. However, the effect of natural haloclines in fjords on parasite dynamics is not well understood. We tagged 48 naturally infested wild sea trout with acoustic depth sensors. The fish were kept inside a small net-pen $(4 \times 4 \times 5 \mathrm{~m}), 12$ at a time, in western Norway during 4 separate time periods in spring 2017 . The sea trout were relatively highly infested with sea lice (prevalence: $100 \%$, mean \pm SD: $68 \pm 58$ lice fish ${ }^{-1}$ ), and a relatively large proportion of the individuals did not survive the trials ( $25 \%$ mortality). The results show that temperature and light were the 2 most important factors explaining the vertical behaviour of the surviving trout. Mobile lice also had a significant effect on depth distribution, where fish with higher abundances of lice were observed at shallower depths. During the $7 \mathrm{~d}$ periods in the net-pen, total sea louse abundance decreased from a mean of 68 to $35 \mathrm{fish}^{-1}$. Surface salinity explained this reduction better than the experienced salinity of the individual fish, suggesting that short-time exposure to very low salinities, rather than long-term exposure to moderate salinities, is the driving force behind the effect of haloclines on reduction in sea lice numbers.
\end{abstract}

KEY WORDS: Acoustic telemetry · Brown trout - Diel vertical migration · Fish behaviour $\cdot$ Sea lice . Vertical behaviour

\section{INTRODUCTION}

Brown trout Salmo trutta is an adaptable species with a remarkable level of plasticity in relation to its life history strategy, both within and across populations (Thorstad et al. 2016). Sea trout is a term for the individuals of brown trout that display an anadromous life history strategy (Thorstad et al. 2016). They spawn in freshwater, and the juveniles remain there for 1-8 yr during the life stage called parr. Parr are somewhat tolerant to saltwater but cannot tolerate full-strength seawater. Therefore, before undertaking their marine feeding migration, they undergo a series of physiological, morphological, and behavioural changes, called smoltification (Thorstad et al.

\footnotetext{
${ }^{*}$ Corresponding author: agnes.marie.mohn@hi.no
}

2016). In line with their anadromous life cycle, usually, both smolts and adult individuals of sea trout emigrate from their rivers in early spring and return to their rivers to spawn or overwinter either the first, second, or third autumn following emigration (Thorstad et al. 2016).

Norwegian rivers are home to some of the last large wild populations of sea trout in the Atlantic Ocean. The corresponding coastline is heavily populated with salmon Salmo salar farms, making up a large proportion of world salmon production (Liu et al. 2011). One of the major criticisms of farmed fish production in net-pens is the environmental impact on local ecosystems, including the potential interactions between disease and parasites of farmed and wild

() The authors 2020. Open Access under Creative Commons by Attribution Licence. Use, distribution and reproduction are unrestricted. Authors and original publication must be credited. 
fish. Of these interactions, the most debated is unquestionably the effect of salmon lice from fish farms on wild salmonid populations, producing a vast number of studies across countries harbouring both wild and farmed salmonids (Agnalt et al. 2017). Salmon louse Lepeophtheirus salmonis is an ectoparasite affecting salmonids, including sea trout (Bjørn \& Finstad 1997), and may cause substantial damage to its host when present in high numbers (Bjørn \& Finstad 1997, Wells et al. 2006, Thorstad et al. 2015). In Norway, salmon lice from fish farms has been documented to be one of the major threats to wild salmon populations (Forseth et al. 2012). The Norwegian government has expressed the ambition of a 5-fold increase in production in the Norwegian aquaculture industry by 2050 (Guttormsen 2017). To amend potential environmental impacts of this increase, a new policy system has been designed, called the traffic light system (Vollset et al. 2017a). The Norwegian coastline has been split up into zones, each to be managed independently based on environmental indicators that define the environmental status of each zone (Guttormsen 2017). Impact severity of salmon lice on wild salmonids is one of these environmental indicators (Guttormsen 2017). The impact severity is quantified through risk assessments based on data from a national surveillance programme, monitoring the level of salmon lice on wild populations of salmonids along the Norwegian coastline (Taranger et al. 2015). As with any monitoring programme, there are limitations to the data, i.e. whether it is representative of the natural population. In addition, data on the abundance of salmon lice on sea trout is currently being used as a proxy for the infestation pressure on wild salmon $S$. salar post-smolts, due to the varying success and high costs related to the methods used to catch salmon post-smolts for surveying of lice occurrence (Taranger et al. 2015, Vollset et al. 2017b). Consequently, understanding how louse abundance on sea trout is impacted by the behaviour of the host is important to be able to link survey data to population-level effects on salmonids.

In areas with high infestation pressure of salmon lice, sea trout with high abundances of the parasite tend to return prematurely to freshwater, often just days or weeks post their emigration from the river (Birkeland \& Jakobsen 1997, Thorstad et al. 2015). Although premature return relieves fish of osmoregulatory stress and aids in shedding the lice, as a result of lice having low tolerance to freshwater (Finstad et al. 1995, Bricknell et al. 2006, Wright et al. 2016), it also represents loss of time at sea. This in turn affects the growth of the trout due to loss of for- aging opportunities, leading to reduced fecundity and reproductive success (Birkeland 1996). However, rivers are not the only possible source of freshwater for sea trout. The high input of freshwater in the inner parts of a fjord system may cause a vertical stratification of the water, where lighter freshwater lies on top of the higher-density saltwater. Sea trout can potentially exploit this top layer of freshwater, triggered by the same mechanisms that cause them to return prematurely. For example, Helland et al. (2015) found that salmonid fish were less likely to have increased infestation levels when abundant freshwater run-off was close to the sampling area. This indicates that the overall prevalence of freshwater in a fjord may influence the abundance of lice on wild salmonid fish. Halttunen et al. (2017) found, using acoustic transmitters, that sea trout positioned themselves in shallower waters and closer to the river in years when salmon louse infestation pressure from fish farms was high, with no difference between the sea trout treated prophylactically against salmon lice and those not treated between years. Serra-Llinares et al. (2020) recently attempted to reverse this study design by releasing artificially infested sea trout tagged with acoustic transmitter tags into an area without fish farms, finding similar patterns, with infested fish spending less time in more saline waters.

However, a criticism of these acoustic telemetry studies that try to link sea louse infestations to fish behaviour is that they (1) lacked fine-scale sampling of the environmental factors and (2) cannot determine the ultimate fate of the salmon lice present on the fish at the start of the study. The aim of the present study was therefore to investigate the role of salmon lice as a factor in the vertical positioning of sea trout at sea in a semi-controlled environment and how this behaviour may impact the lice abundance on the fish. The behaviour of 48 sea trout naturally infested with salmon lice was quantified by tracking their vertical positioning while kept inside a small net-pen. Depth data were subsequently linked to fine-scale data on light intensity, salinity, temperature, salmon lice abundance on individual trout, and salmon louse-related damage.

\section{MATERIALS AND METHODS}

\subsection{Study area and design}

The study was located in Herdlefjorden, in the county Hordaland, ca. $25 \mathrm{~km}$ northwest of Bergen (Norway). Hordaland is a county with high aquacul- 
ture intensity, with 176 active salmonid aquaculture facilities present during 2017 (Norwegian Directorate of Fisheries, https://www.fiskeridir.no/English/ Aquaculture/Statistics/Atlantic-salmon-and-rainbowtrout). The specific location of the study was a sheltered bay in the northern part of the fjord $\left(60.571^{\circ} \mathrm{N}\right.$, $5.016^{\circ} \mathrm{E}$ ), where there is a high level of freshwater impact due to 2 small river outlets nearby (see Fig. S1 in the Supplement at www.int-res.com/articles/suppl/ q012p215_supp.pdf). The study was conducted in a $5 \mathrm{~m}$ deep net-pen $(4 \times 4 \times 5 \mathrm{~m})$. Four sea trials were conducted between 10 May and 25 June, each lasting 8-11 d (Table 1). In each trial, the pen was stocked with 12 sea trout Salmo trutta with surgically implanted acoustic depth sensors (see below). The project was approved by the National Animal Welfare Committee (application no. 11838).

\subsection{Fish handling}

Fish were caught in 2 trap nets, a passive fishing gear. The trap net design mainly consists of a fine meshed leading net attached to shore with a chamber in the end and is further described in Barlaup et al. (2013). The trapping chamber was checked and emptied every $24 \mathrm{~h}$. Upon capture, individual fish were first anaesthetized (80 $\mathrm{mg} \mathrm{l}^{-1}$ tricaine methanesulfonate; Finquel vet, Scan Aqua). We then measured the mass $(\mathrm{g})$ and total length $(\mathrm{mm})$ of the fish, before tagging it. A total of 48 sea trout (Table 2) were tagged with an acoustic tag with a depth sensor (Thelmabiotel ADT-LP-7, 3, transmit interval: 30-90 s, lifetime: $150 \mathrm{~d}$, resolution: $10 \mathrm{~cm}$ ). To oxygenate the fish and to ensure that the fish was anaesthetized through the whole procedure, seawater with a tricaine concentration of $40 \mathrm{mg} \mathrm{l}^{-1}$ was continuously flushed over the gills using a ca. $2 \mathrm{~m}$ long silicone tube. A small incision (approximately $10 \mathrm{~mm}$ long)

Table 1. Key environmental information for the 4 trials. Temperature and salinity data were sampled throughout the whole study period at $0.2 \mathrm{~m}$ depth using loggers. Light measurements were downloaded from a meteorological station (University of Bergen, Norway). Dates are yr-mo-d

\begin{tabular}{|lccccc|}
\hline Trial & Start date & Stop date & $\begin{array}{c}\text { Mean } \pm \mathrm{SD} \\
\text { surface } \\
\text { temperature } \\
\left({ }^{\circ} \mathrm{C}\right)\end{array}$ & $\begin{array}{c}\text { Mean } \pm \mathrm{SD} \\
\text { surface } \\
\text { salinity } \\
(\mathrm{ppt})\end{array}$ & $\begin{array}{c}\text { Mean } \pm \mathrm{SD} \\
\text { surface } \\
\text { light intensity } \\
\left(\mu \mathrm{\mu mol} \mathrm{s}{ }^{-1} \mathrm{~m}^{-2}\right)\end{array}$ \\
\hline 1 & $2017-05-10$ & $2017-05-17$ & $11.2 \pm 0.8$ & $19.3 \pm 3.5$ & $375 \pm 562$ \\
2 & $2017-05-22$ & $2017-06-01$ & $14.1 \pm 1.0$ & $17.1 \pm 1.7$ & $517 \pm 674$ \\
3 & $2017-06-02$ & $2017-06-12$ & $13.6 \pm 0.7$ & $15.3 \pm 1.7$ & $308 \pm 433$ \\
4 & $2017-06-15$ & $2017-06-25$ & $14.3 \pm 0.8$ & $13.2 \pm 2.3$ & $336 \pm 476$ \\
\hline
\end{tabular}

was made mid-ventrally just anterior to the pelvic girdle or posterior to the pectoral fins with a sterile scalpel (Swann-Morton no. 12). The tag was pre-sterilized with $96 \%$ ethanol, then inserted into the abdominal cavity. The incision was closed with 2 monofilament non-absorbable sutures (EH7144H), together with tissue adhesive (Histoacryl). After the first trial, we began using a broad-spectrum antibiotic cream (Terramycin-Polymyxin B) to reduce the risk of potential bacterial infections in the wound. The tag was coated wth a thin layer of the cream prior to implantation. Lastly, to reduce uncertainty related to handling-induced louse detachment, each of the salmon lice Lepeophtheirus salmonis present was counted and identified to one of the following life stages: copepodid, chalimus 1, chalimus 2, preadult (no distinguishing of sex), adult male, or adult female. Individuals of another louse species, Caligus elongatus, were also counted, but without identifying life stage or sex. Skin damage associated with the lice was quantified by a scoring system of $0-3$ (Table S1).

Tag detections were recorded with 6 Vemco acoustic receivers (VR2W-69kHz) attached to the outside of the net-pen framework. As we wanted 12 fish with minimum variance in size, the fish sometimes had to be tagged over several days, due to insufficient catches in the trap nets. During transportation between the trap nets, the tagging location, and the net-pen, and for storage during tagging, fish were kept in a tub with a constant supply of water. The fish handling was done as efficiently as possible. The specific handling time varied depending on catches. Time from capture to release never exceeded $4 \mathrm{~h}$, while the time from sedation to placement into a recovery tank was approximately $10 \mathrm{~min}$. Sea lice counting increased the time during sedation and contributed to the handling time being somewhat longer than normal for these operations. The fish were transported and released inside the net-pen immediately after all handling procedures were carried out.

At the end of each trial, fish were killed with an overdose of tricaine and a blow to the head. Louse abundance and damage, fish mass, and fish length were then carefully registered in an identical procedure to the one applied during tagging, but in the opposite order. Blood samples were also collected from each fish in Trials 2,3 , and 4 before the tag was retrieved for reuse in the following trials. Blood samples 
Table 2. Key measurements of all fish (sea trout Salmo trutta). Missing values indicates missing data. Survival: $0=$ died during the trial, 1 = survived the trial. Htc: haematocrit. Lice abundance: Lepeophtheirus salmonis

\begin{tabular}{|c|c|c|c|c|c|c|c|}
\hline $\begin{array}{l}\text { Fish } \\
\text { ID }\end{array}$ & Trial & $\begin{array}{c}\text { Survival } \\
(0 / 1)\end{array}$ & $\begin{array}{l}\text { Weight } \\
\text { (g) }\end{array}$ & $\begin{array}{c}\text { Length } \\
(\mathrm{mm})\end{array}$ & $\begin{array}{l}\text { Lice abur } \\
\text { Attached }\end{array}$ & $\begin{array}{l}\text { ndance } \\
\text { Mobile }\end{array}$ & $\begin{array}{l}\text { Hct } \\
(\%)\end{array}$ \\
\hline 110 & 1 & 0 & 205 & 302 & 8 & 7 & \\
\hline 111 & 1 & 0 & 447 & 400 & 81 & 57 & \\
\hline 112 & 1 & 1 & 493 & 397 & 28 & 78 & \\
\hline 113 & 1 & 0 & 483 & 386 & 7 & 11 & \\
\hline 114 & 1 & 1 & 791 & 440 & 5 & 40 & \\
\hline 115 & 1 & 1 & 355 & 360 & 45 & 19 & \\
\hline 116 & 1 & 1 & 278 & 325 & 22 & 40 & \\
\hline 117 & 1 & 0 & 247 & 320 & 12 & 12 & \\
\hline 118 & 1 & 1 & 590 & 425 & 9 & 28 & \\
\hline 119 & 1 & 1 & 805 & 450 & 19 & 49 & \\
\hline 121 & 1 & 0 & 361 & 370 & 0 & 9 & \\
\hline 210 & 2 & 0 & 393 & 370 & 6 & 10 & \\
\hline 211 & 2 & 1 & 507 & 410 & 24 & 80 & 30.8 \\
\hline 212 & 2 & 1 & 366 & 355 & 37 & 28 & 41.5 \\
\hline 213 & 2 & 1 & 1424 & 550 & 139 & 58 & 46.8 \\
\hline 214 & 2 & 1 & 210 & 300 & 24 & 5 & 21.7 \\
\hline 215 & 2 & 0 & 759 & 425 & 33 & 27 & \\
\hline 216 & 2 & 1 & 714 & 417 & 9 & 10 & 37.7 \\
\hline 217 & 2 & 1 & 760 & 430 & 5 & 36 & 34.4 \\
\hline 218 & 2 & 0 & 388 & 368 & 4 & 10 & \\
\hline 219 & 2 & 1 & 382 & 351 & 16 & 9 & 47.0 \\
\hline 220 & 2 & 1 & 441 & 376 & 15 & 1 & 39.5 \\
\hline 221 & 2 & 0 & 760 & 435 & 129 & 12 & \\
\hline 310 & 3 & 1 & 330 & 330 & 12 & 22 & 39.4 \\
\hline 311 & 3 & 1 & 523 & 410 & 4 & 20 & 37.2 \\
\hline 312 & 3 & 1 & 346 & 340 & 19 & 25 & 43.1 \\
\hline 313 & 3 & 1 & 243 & 316 & 0 & 20 & 7.1 \\
\hline 314 & 3 & 1 & 236 & 300 & 75 & 35 & 29.0 \\
\hline 315 & 3 & 1 & 216 & 306 & 41 & 35 & 11.2 \\
\hline 316 & 3 & 1 & 719 & 425 & 114 & 34 & 42.3 \\
\hline 317 & 3 & 1 & 464 & 379 & 46 & 83 & 40.1 \\
\hline 318 & 3 & 1 & 655 & 410 & 42 & 42 & 43.4 \\
\hline 319 & 3 & 1 & 603 & 430 & 11 & 59 & 33.5 \\
\hline 320 & 3 & 1 & 1299 & 500 & 2 & 34 & 41.7 \\
\hline 321 & 3 & 1 & 468 & 378 & 42 & 54 & 50.5 \\
\hline 410 & 4 & 1 & 702 & 432 & 7 & 24 & 40.3 \\
\hline 411 & 4 & 1 & 757 & 442 & 17 & 32 & 40.5 \\
\hline 412 & 4 & 0 & 502 & 393 & 52 & 30 & \\
\hline 413 & 4 & 0 & 208 & 289 & 5 & 8 & \\
\hline 414 & 4 & 1 & $>2000$ & 530 & 187 & 112 & 45.4 \\
\hline 415 & 4 & 1 & 580 & 415 & 9 & 44 & 45.9 \\
\hline 416 & 4 & 1 & 314 & 330 & 1 & 9 & 41.7 \\
\hline 417 & 4 & 1 & 516 & 384 & 20 & 35 & 39.5 \\
\hline 418 & 4 & 1 & 585 & 413 & 2 & 24 & 41.3 \\
\hline 419 & 4 & 1 & 375 & 355 & 61 & 32 & 34.7 \\
\hline 420 & 4 & 1 & 498 & 379 & 1 & 16 & 45.3 \\
\hline 421 & 4 & 0 & 301 & 313 & 1 & 11 & \\
\hline
\end{tabular}

were taken from the caudal blood vessels. Haematocrit (Hct) and leukocrit (Lct) levels were determined to be able to readily identify individuals compromised by leaky incisions (low Hct) and/or secondary infections (abnormal Lct). Fish were not fed during the trials.

\subsection{Quantification of abiotic factors}

Conductivity and temperature were logged continuously during all 4 trials with the use of 5 loggers (Solinst, Levelogger Edge 3003) at depths of $0.2,0.5,1,2.5$, and $5 \mathrm{~m}$. Loggers were attached to a rope at the defined depth intervals and programmed to record conductivity and temperature every $5 \mathrm{~min}$. The rope was attached to the top frame of the net-pen at one end and had an anchor (approximately $2 \mathrm{~kg}$ ) attached at the other end. The data were linked to the time and depth of the individual registrations to estimate the conditions experienced by the fish. Conductivity data was converted to salinity using the package marelac (Soetaert et al. 2016) in RStudio (R Core Team 2014). Pressure was set to 0 , as no data on pressure was obtained, and it also did not seem to serve as a major factor for salinity when testing different values for the variable.

For light measurements, a light sensor logger (LI-COR Environmental, LI-1500) was used together with an underwater quantum sensor (LI192). Light intensity was measured at $1 \mathrm{~m}$ depth intervals $(0,1,2,3,4$, and $5 \mathrm{~m})$ at 3 different locations inside the net-pen at the start of each new trial, in 3 of the 4 trials $(2017.06 .22,2017.06 .02$, and 2017.06.15). The quantum sensor was mounted to a 2009S Lowering Frame with the sensor facing upwards. The depth of each measurement was estimated by matching pre-measured tape markings with an interval of $1 \mathrm{~m}$ on the attached rope with the water surface. The measurements were used to calculate the light attenuation constant $k$ using the Beer-Lambert law equation:

$$
I_{D}=I_{0} e^{-k \cdot D}
$$

where $D$ is a specific depth, $I_{D}$ is the corresponding light intensity at this depth, $I_{0}$ represents surface light intensity, and $k$ is the light attenuation coefficient. Calculations were done for each set of measurements (3 replications of $0-5 \mathrm{~m}$ ). The $k$ from trial $2(k=0.38)$ was excluded from further analysis, since it deviated from $k$ in Trials 3 and 4 ( $k=0.71$ and $k=0.69$, respectively).

Data on surface light intensity was downloaded from a meteorological station owned by the geophysical institute at the University of Bergen (Været i Bergen; https://veret.gfi.uib.no/). The data had a 10 min resolution and was used to model the light intensity at different depths, together with the mean $k$ from Trials 3 and 4, again using the Beer-Lambert law equation, our Eq. (1). 


\subsection{Data filtering}

Before initiation of the study, tags were tested at the water surface for accurate calibration. Ten out of 12 tags needed further calibration, which was done by subtracting the offset detected in the surface test from all sensor values. Calibrations were controlled by filtering detections for negative values. Nine tags (numbered 10, 11, 12, 13, 14, 15, 17, 18, and 21) had negative sensor values and were hence recalibrated by subtracting the equivalent positive value from the original offset value. No further range tests were carried out, as this was deemed unnecessary due to the size of the study area and the density of receivers.

A total of 851230 detections of vertical positioning were registered and downloaded from 6 receivers throughout the full study period. Of these, some were discarded due to false transmitter identification (ID) codes. Any visit made to the location was classified as a disturbance. Disturbances to the study were logged, and all data within the trial of the disturbance (start of disturbance minus 15 min to end of disturbance plus $15 \mathrm{~min}$ ) was flagged in the dataset and excluded from the analysis. Fish that died during the study period were flagged in the dataset (12 fish) and excluded from further analysis. Individuals showed signs of stress-induced behaviour at the beginning of each trial, as seen in individual plots of depth use (see Fig. S2a-d). Therefore, a recovery time of $2 \mathrm{~d}$ was used and detections within this time period were flagged in the dataset and excluded from further analysis. Two fish (IDs 313 and 315) from Trial 3 were also flagged due to critically low Hct levels (7.1 and $11.2 \%$, respectively). Hence, after this filtering, a total of 473996 detections (56\%) among 35 individuals with their associated biotic and abiotic sample values remained for statistical modelling and analysis.

\subsection{Data analysis}

Data were analyzed according to Zuur et al. (2009), using R. A linear mixed-effects model (Gałecki \& Burzykowski 2013) was used to model depth use of the sea trout. On the basis of the a priori hypothesis on salinity being the main driving force in the potential relationship between depth and louse abundance, we considered whether experienced salinity would be a better response factor for testing the hypothesis. However, this was outweighed by the high resolution of the depth measurements compared to that of the salinity data, as the factors also are strongly correlated. The ID of each fish, hence the individual fish, was used to define a random intercept. Vertical positioning in terms of water depth was log transformed due to behavioural responses being skewed towards the surface, with fewer observations of 'dives' towards the lower part of the net-pen. In this analysis, mean number of lice per gram of fish between the first and second estimations, fish length, surface temperature (sampled at $0.2 \mathrm{~m}$ depth), surface salinity (sampled at $0.2 \mathrm{~m}$ depth), and surface light were included as explanatory variables. The linearity between depth and the 4 explanatory variables was explored using smooth spline plots. It was decided to log transform the louse variable, as there appeared to be a $\log -\log$ relationship between depth use and lice. The same was done for fish length and surface light. The others were kept linear, as there were no clear patterns in the data. Temperature and salinity at other depths, or the difference between surface and bottom depth, were explored as explanatory variables, but could not be included due to strong correlation with the surface measurements.

Fine-scale behaviour was explored by looking at histograms of changes in depth (delta) from one detection to the next. Out of the 473996 detections, 462848 showed a delta $\leq 1$, meaning that the fish remained within a $1 \mathrm{~m}$ interval of water depth in $97.7 \%$ of all time intervals of the dataset. To synchronize the frequencies of variables, observations for vertical positioning were averaged across every $10 \mathrm{~min}$ to do observations on the finest scale according to the explanatory variables (i.e. light measurements had $10 \mathrm{~min}$ intervals) (33 144 detections). Since the observations were autocorrelated (i.e. an observation at one time step was strongly correlated to the observation at the next time step), a serial autocorrelation structure was explored (AR1). For model selection, the Aikake information criterion (AIC) was then applied to compare this model to a variant with no lag structure (Burnham \& Anderson 2002). The AIC clearly suggested that a model including AR1 was superior. However, the autocorrelation in the current model did not decay as fast as the AR1 model. Thus, it was decided to explore more complex autoregressive-moving average (ARMA) functions with deeper lag structures. However, although more complex models did reduce AIC values, they did not influence parameter estimates and their variance. Consequently, the simple AR1 model was selected. The full model was tested with 3 different louse parameters: total lice per gram of fish, mobile lice per gram of fish, and score of louse-caused damage, and compared using the likelihood ratio test in $\mathrm{R}$ ( $\mathrm{R}$ Core Team 2014). The model with the best fit became the target of further selection by using the dredge 
function in the MuMIn package (Barton 2018) in R ( $R$ Core Team 2014). Further interactions, according to the a priori hypotheses, were tested by comparing AIC, again by the use of likelihood ratio tests.

Change in louse abundance from initiation to termination of each trial was modelled using a generalized linear model (GLM), predicting louse abundance at termination according to a priori-decided parameters, with data averaged across individuals $(\mathrm{n}=35)$. End-of-trial total louse abundance, end-oftrial abundance of louse mobile stages, and end-oftrial abundance of attached stages were modelled separately, and parameters included start-of-trial total louse abundance, start-of-trial mobile louse abundance, start-of-trial attached louse abundance, mean experienced salinity, mean experienced temperature, and surface salinity. Fish mass was also included as a predictor. No interactions were included, as we deemed the dataset insufficient. Selection in all models was done using the dredge function in $\mathrm{R}$ (R Core Team 2014).

A total of 12 fish died during the study: 5 in Trial 1, 4 in Trial 2, and 3 in Trial 4. A GLM binomial model was explored to evaluate what factors were causative of the mortality, but due to the low sample size, the power of the analysis was too low to reveal any pattern. It was not evident that the fish that died experienced particularly high levels of salmon lice.

\section{RESULTS}

\subsection{Temperature and salinity}

Salinity decreased throughout the study from a mean of $19.3 \mathrm{ppt}$ in the first trial to $13.2 \mathrm{ppt}$ in the last (Fig. 1a, Table 1). In contrast, temperature increased from a mean of $11.2^{\circ} \mathrm{C}$ in the first trial to $14.3^{\circ} \mathrm{C}$ in the last trial (Fig. 1b, Table 1)

\subsection{Depth preference}

Fish that died exhibited a deviating vertical behaviour (Fig. 2), probably explained by stress, as the same tendencies were seen during the $2 \mathrm{~d}$ time period set as recovery time (Figs. $3 \& 4$ ). In Trial 3, the fish generally seemed less stressed, as less deviation at depth registrations were seen in this time period (Fig. S2c). This was also the only trial where none of the fish died during the experiment. This could not be linked to anything specific, as the methodology was the same in all trials. The observed data showed that the sea trout, in general, had a very narrow depth range, spending over $80 \%$ of their time above $2.5 \mathrm{~m}$. By plotting the depth registrations, it also became evident that sea trout exhibited diel migrations, staying in slightly shallower depths during the night and deeper during the day (mean depth: 0.63 and $0.77 \mathrm{~m}$, respectively).

All 3 louse parameters were examined separately, and mobile lice turned out to be the most significant predictor and therefore used in further model selection. According to the top model (Table 3), mobile lice $(p=0.033)$ and surface temperature $(p<0.001)$ had a negative effect on depth. This implies that fish occupied shallower depths with greater louse counts and temperature values, while surface light had a slight positive effect $(p=0.012)$, meaning that the fish inhabited deeper habitat when light intensities were high. In addition, surface salinity $(p=0.135)$ was included in the top model, despite not being significant $(p>0.05)$. The parameter estimate was positive, meaning that fish swam shallower with low surface salinities.

These results also coincided well with the initial patterns observed in the raw data for both temperature and lice, but less for light, as there seemed to be a stronger relationship in the data than what showed up in the top model (Fig. 3). The same applied to the effect of surface salinity. A reason for this lack of pattern was most likely due to the most important component of the top model being the random effect of the individual, which was highly variable (Table 3), illustrated as the different grey lines in Fig. 3. These results indicate that the different individuals' overall choice played a larger part in depth preference than the response to environmental factors. The consequence was a model that seemed to be less sensitive to environmental factors than what was expected after plotting of the observed data (Figs. 4 \& 5).

Another critical point was also that the top model seemingly did a poor job in predicting occurrences of sporadic dives into deep sections of the cage. To illustrate this, the observed depth was compared with the depth predicted by the top model using violin plots (Fig. S3a,b). However, the model did distinguish between the categories defined by the abundance of mobile lice, showing that highly infested individuals stayed closer to the surface.

\subsection{Impact on louse level}

The average reduction in louse level during the trial period was large in all 4 trials (68 \pm 58 to $35 \pm 18$ 
a) Salinity over time

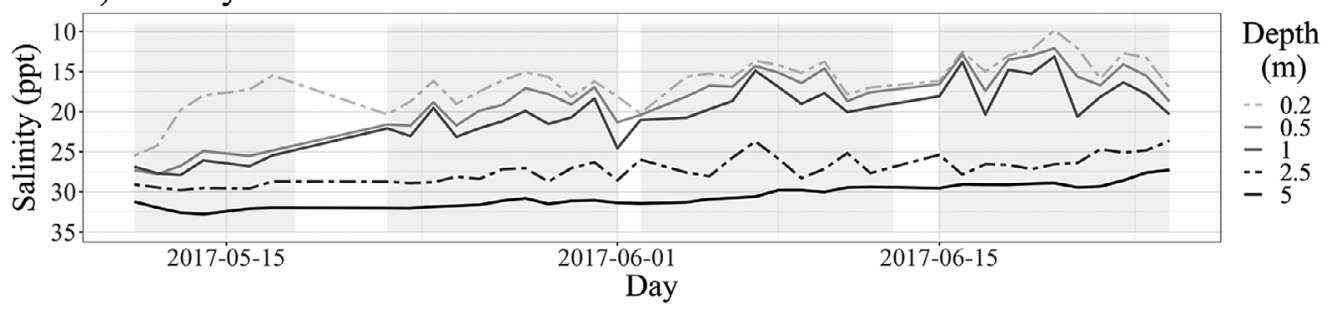

b) Temperature over time

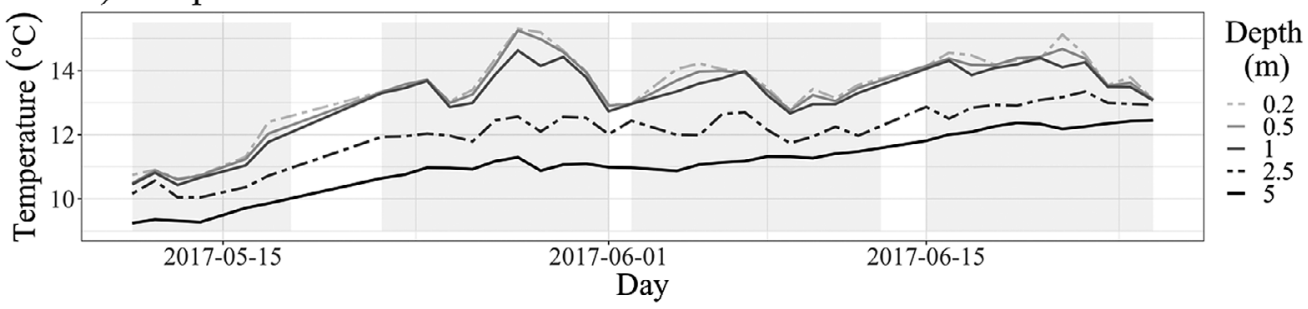

c) Mean salinity
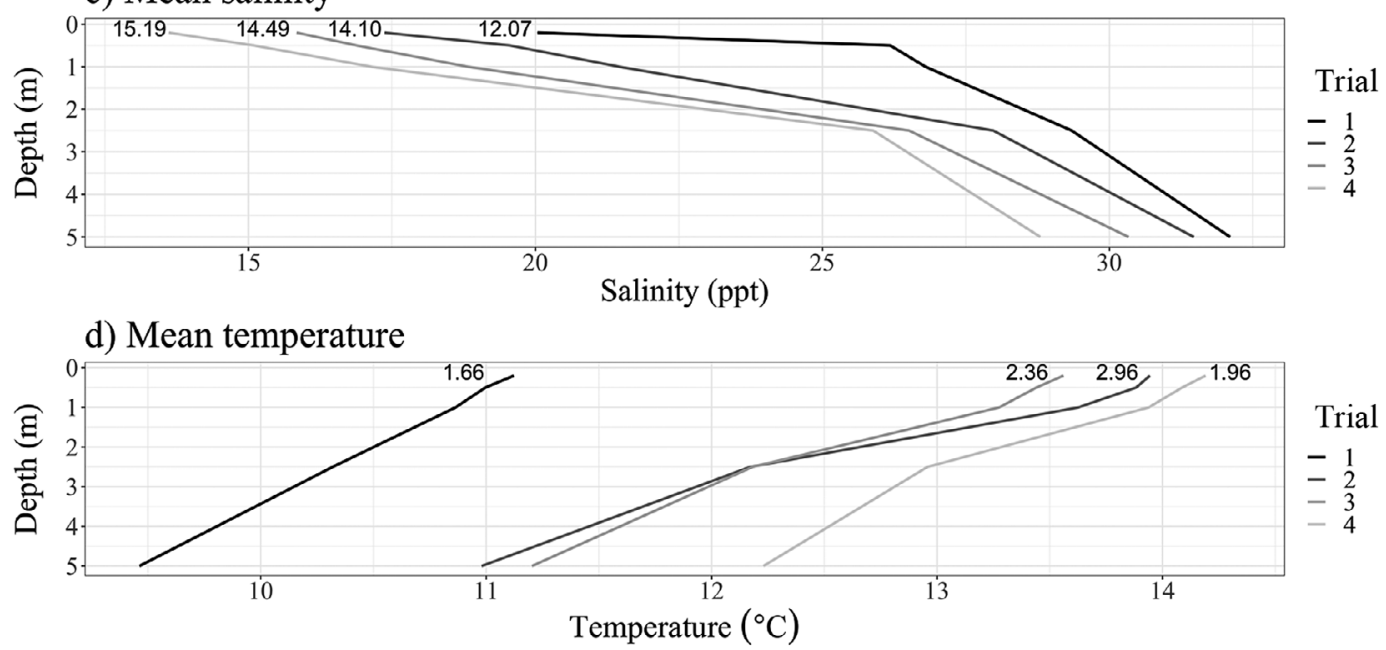

Fig. 1. Mean daily (a) salinity and (b) temperature at 0.2-5 $\mathrm{m}$ depth throughout the whole study period (10 May to $25 \mathrm{June} 2017$ ); and depth plotted against mean (c) salinity and (d) temperature for each of the 4 trials. Number at the top of the data line in (c) and (d) represents the range between the uppermost $(0.2 \mathrm{~m})$ and lowermost $(5 \mathrm{~m})$ sample depths for each trial. Shaded areas in

(a) and (b) indicate the 4 trial periods

lice fish $^{-1}$, mean $\pm \mathrm{SD}$ ). This was illustrated by plotting individual louse counts at initiation and termination against each other (Fig. 6a). Most fell beneath the 1:1 line (Fig. 6a), while only a few individuals recruited lice (i.e. were above the 1:1 line). The same applies when looking at just the mobile stages, with slightly more recruitment (Fig. 6b). For attached stages (Fig. 6c), all individuals fell beneath or on the 1:1 line.

When modelling end-of-trial louse abundance, fish mass turned up as a predictor for all stages of louse development (Table 4). The parameter estimate was positive in all top models, implying that higher mass of the fish was associated with higher levels of lice.

All 5 top models in all selection sets included lice at the start (Table S2b). The parameter estimates were positive and consistent in size in all 5 models, mean- ing that more lice at the start contributed to more lice at the end. When modelling for the end-of-trial abundance of mobile lice, the top model included both the start-of-trial abundance of mobile and attached louse stages (Table S2b, model selection 3). Both parameter estimates were positive and consistent in size in all models, but the estimate for mobile lice was more than twice the size of the one for attached louse stages. Hence, mobile lice was the primary predictor, but attached lice also played a part, likely due to recruitment of attached lice into mobile stages with time. For the model selection for the end-of-trial abundance of attached lice, start-of-trial attached louse abundance was included in all 5 models, with a parameter estimate that was positive and consistent in size throughout all models (Table S2b, model 
a)

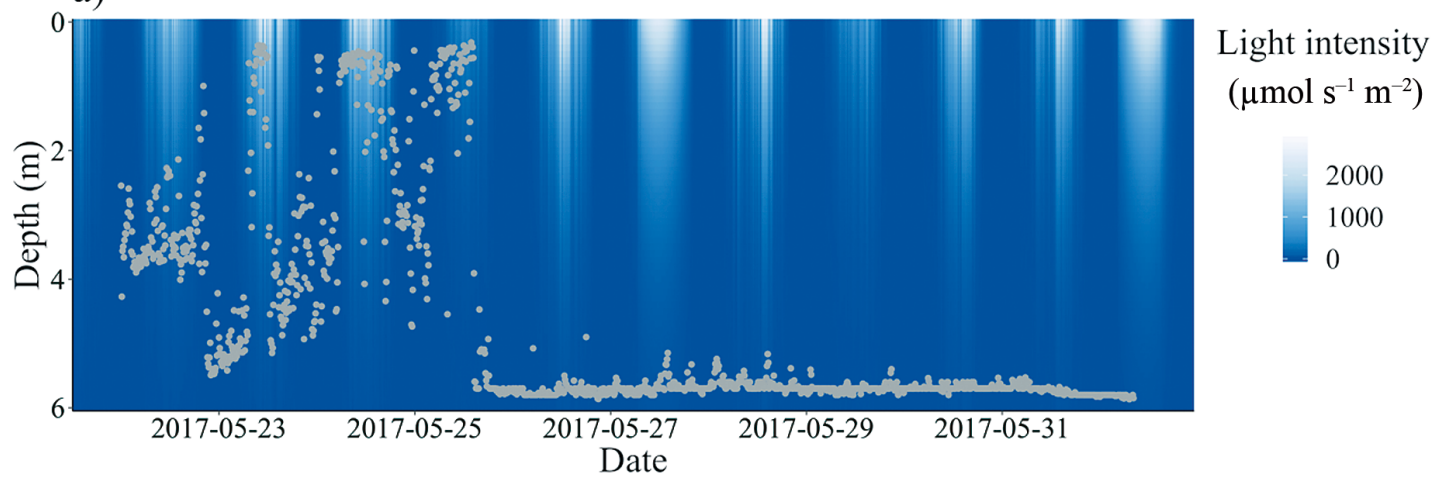

b)

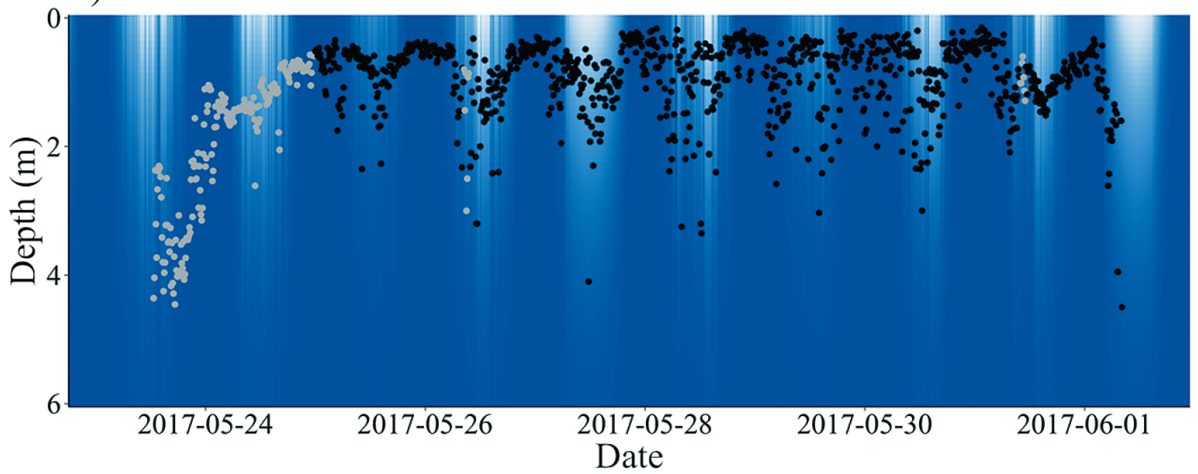

c)

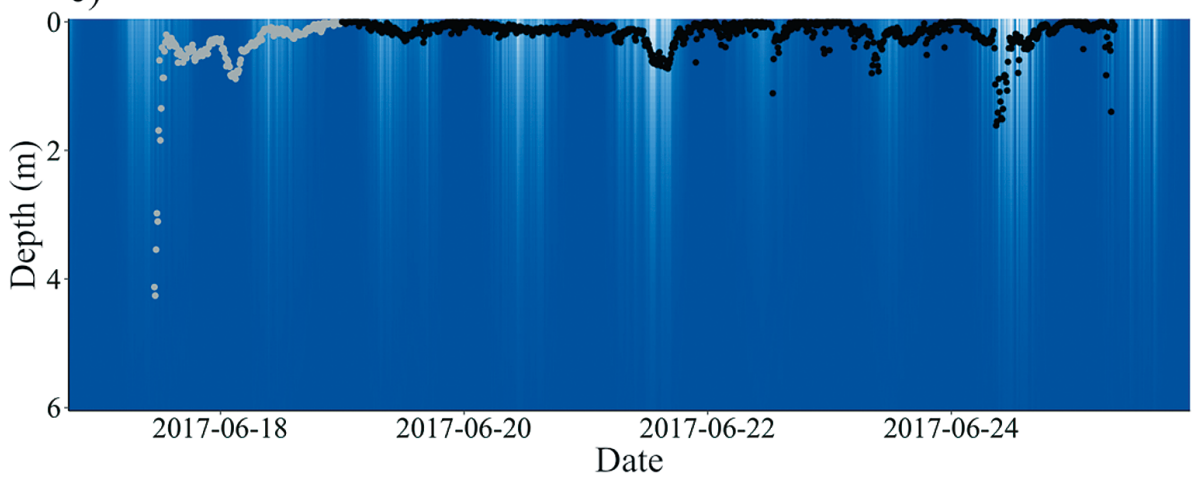

Fig. 2. Vertical distribution of Salmo trutta. Grey points represent data excluded from the analysis either due to mortality, recovery period, or disturbances of the area. See details on data filtering in section 2.4. (a) Fish 210, (b) Fish 220, (c) Fish 419. See Table 2 for more details on the individual fish

selection 4). Also, start-of-trial mobile louse abundance was included as a predictor in 2 of the 5 models, including the top model. The estimate was small and negative, meaning lower values of end-of-trial attached louse abundance when there were high values of start-of-trial mobile louse abundance.

Surface salinity was included in 3 of the 5 top models for end-of-trial total louse abundance, and in all 5 models for end-of-trial mobile louse abundance, including the top model in both model selection sets $(p<0.01)$. It was more or less consistent in size and positive in both cases, meaning there were higher values of total louse abundance and mobile louse abundance at the end of trials when the surface salinity was high, and vice versa.

Experienced temperature was included as a parameter in model selections 1 and 2 (Table S2b) for start-of-trial total abundance and start-of-trial attached louse abundance. The parameter estimate was negative in both cases, showing that there were less lice at the end of the experiment when temperatures were high. For end-of-trial attached louse abundance, it was found in all 5 models, including the top model when strongly influential individuals 
a)

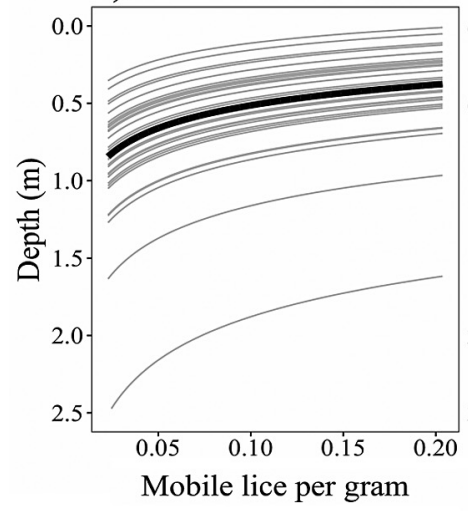

b)

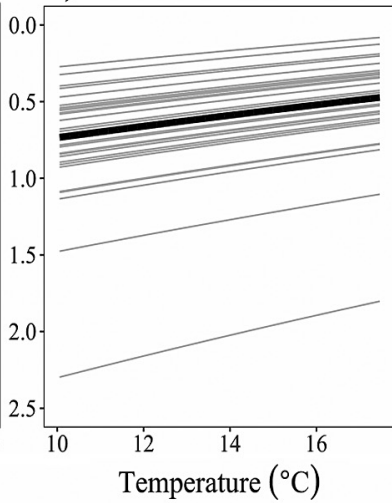

c)

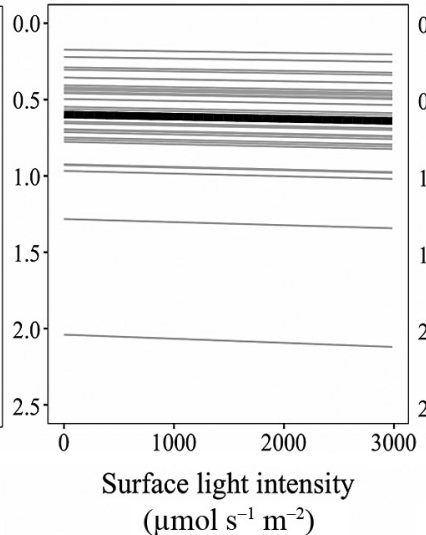

d)

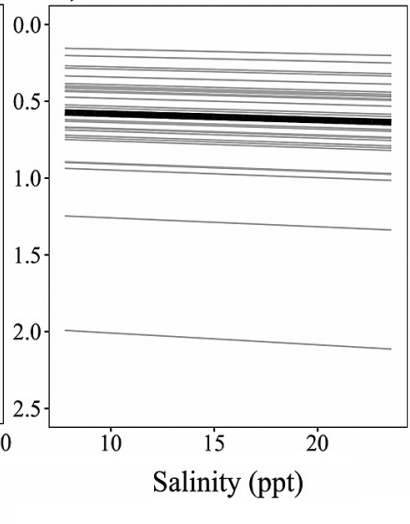

Fig. 3. Plots of predicted Salmo trutta depth against the 4 parameters: (a) mobile lice per gram of fish $\left(L_{i}^{\mathrm{MOB}}\right)$, (b) surface temperature $\left(T_{t}^{\text {up }}\right)$, (c) surface light intensity $\left(\log C_{t}\right)$, and $(\mathrm{d})$ surface salinity $\left(S_{t}^{\text {up }}\right)$, included in the best-fitting model for depth use (Table 3), fitted with a smoothing line (black)

a)

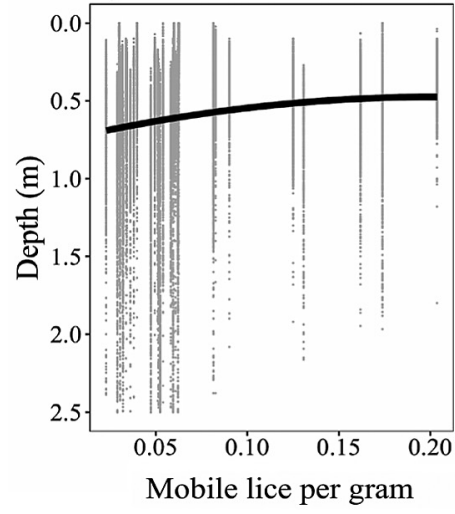

b)

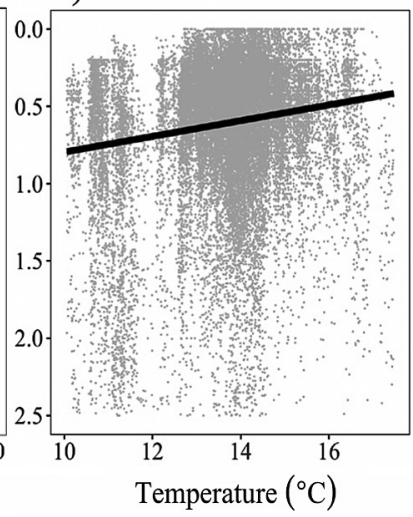

c)

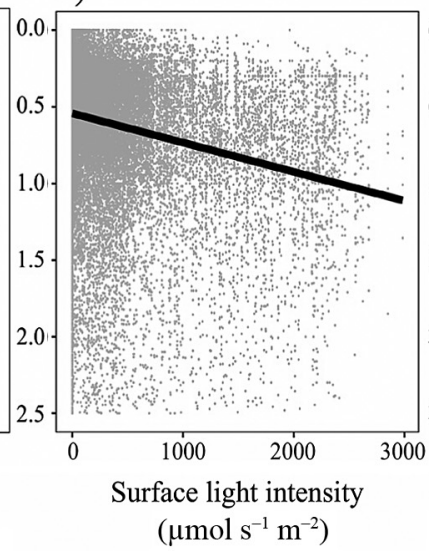

d)

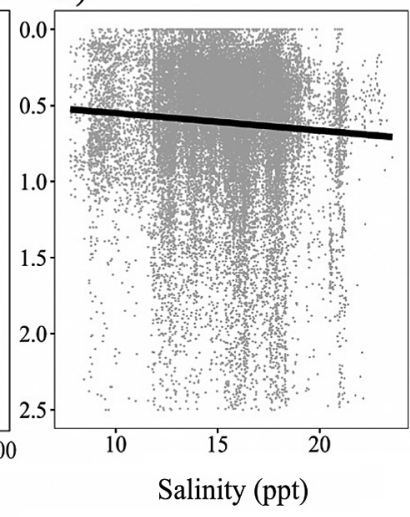

Fig. 4. Raw data of Salmo trutta depth registrations (grey) plotted against the 4 parameters: (a) mobile lice per gram of fish ( $L_{i}^{\mathrm{MOB}}$ ), (b) surface temperature $\left(T_{t}^{\text {up }}\right)$, (c) surface light intensity $\left(\log C_{t}\right)$, and (d) surface salinity $\left(S_{t}^{\text {up }}\right)$, included in the best-fitting model for depth use (Table 3 ), fitted with a smoothing line (black)

Table 3. Analysis of Salmo trutta swimming depth $\left(D_{i t}\right)$. Top model from model selection 1 (Table S2a in the Supplement), where $\beta_{0}$ is the intercept, $C_{t}$ is surface light intensity, $T_{t}^{\text {up }}$ is surface temperature $(0.2 \mathrm{~m}), S_{t}^{\text {up }}$ is surface salinity $(0.2 \mathrm{~m})$, and $L_{i}^{\mathrm{MOB}}$ is mobile lice per gram of fish. $i$ : variation in the factor across individuals; $t$ : variation across time; SD: standard deviation; Phi: correlation coefficient. AR1 is the same autocorrelation structure as described in section 2.5

\begin{tabular}{|lcr|}
\hline Top model, $\log D_{i t} \sim$ & Estimate & $\mathrm{p}$ \\
\hline Fixed effects & 0.363 & 0.052 \\
$\beta_{0}$ & $8.8 \times 10^{-6}$ & 0.012 \\
$\log C_{t}$ & -0.022 & $<0.001$ \\
$T_{t}^{\mathrm{up}}$ & -0.134 & 0.033 \\
$\log L_{i}^{\mathrm{MOB}}$ & 0.003 & 0.135 \\
$S_{t}^{\mathrm{up}}$ & & \\
Random effects & 0.184 & \\
SD $\beta_{0}$ & $\mathrm{Phi}$ & \\
Autocorrelation & & \\
AR1 & & \\
\hline
\end{tabular}

(IDs 115 and 414) were kept in the data. When removed, end-of-trial attached louse abundance was excluded as a predictor from 3 out of 5 models, including the top model, and the whole model seemingly collapsed. For end-of-trial total louse abundance, surface temperature was found in 3 out of the 5 best models, including the second-best model. The change in AIC ( $\triangle \mathrm{AIC})$ from the top model was low, but including it changed the intercept significantly (from -33.540 to 75.370 ). This could indicate lack of robustness or stability in parts of the model. As total louse abundance was a function of attached and mobile louse abundance, the effect of removing the influential individuals in the modelling of end-of-trial total louse abundance was explored. When doing so, surface salinity was excluded from the top model, while experienced temperature came up as a predictor in all models, including the top model. In Fig. S4, 


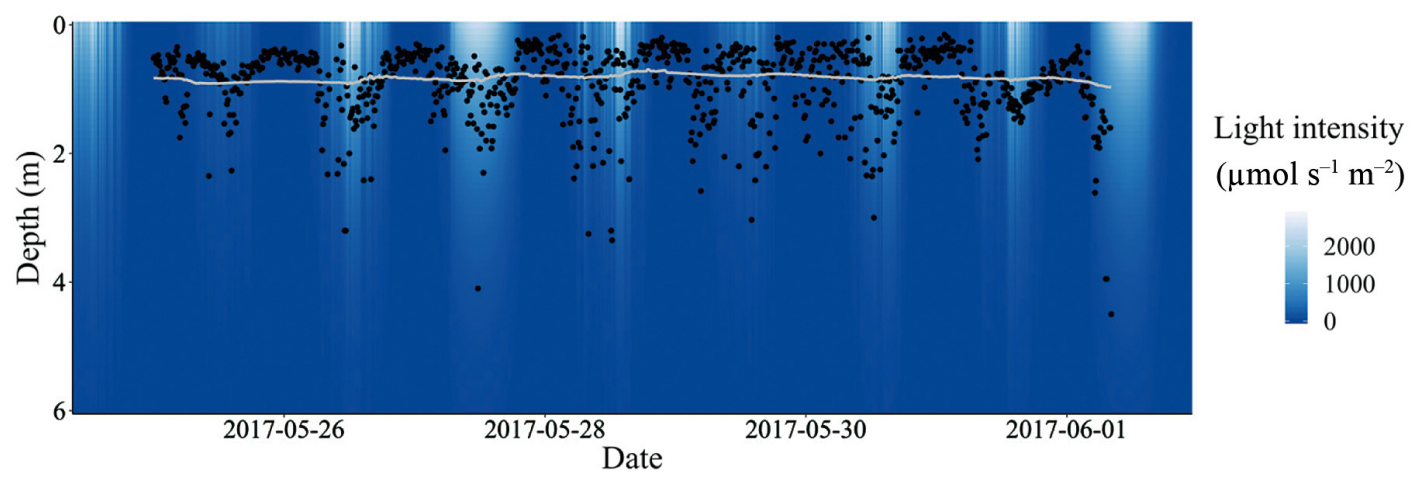

Fig. 5. Observed vertical distribution (black dots) of Salmo trutta, fish 220 (1 mobile louse at the initiation of the experiment, see Table 2), after data filtration (see Section 2.4). Grey line: the vertical distribution predicted by the chosen fitting model

(Table 3) for the same individual. The data has been retransformed from log to normal distribution
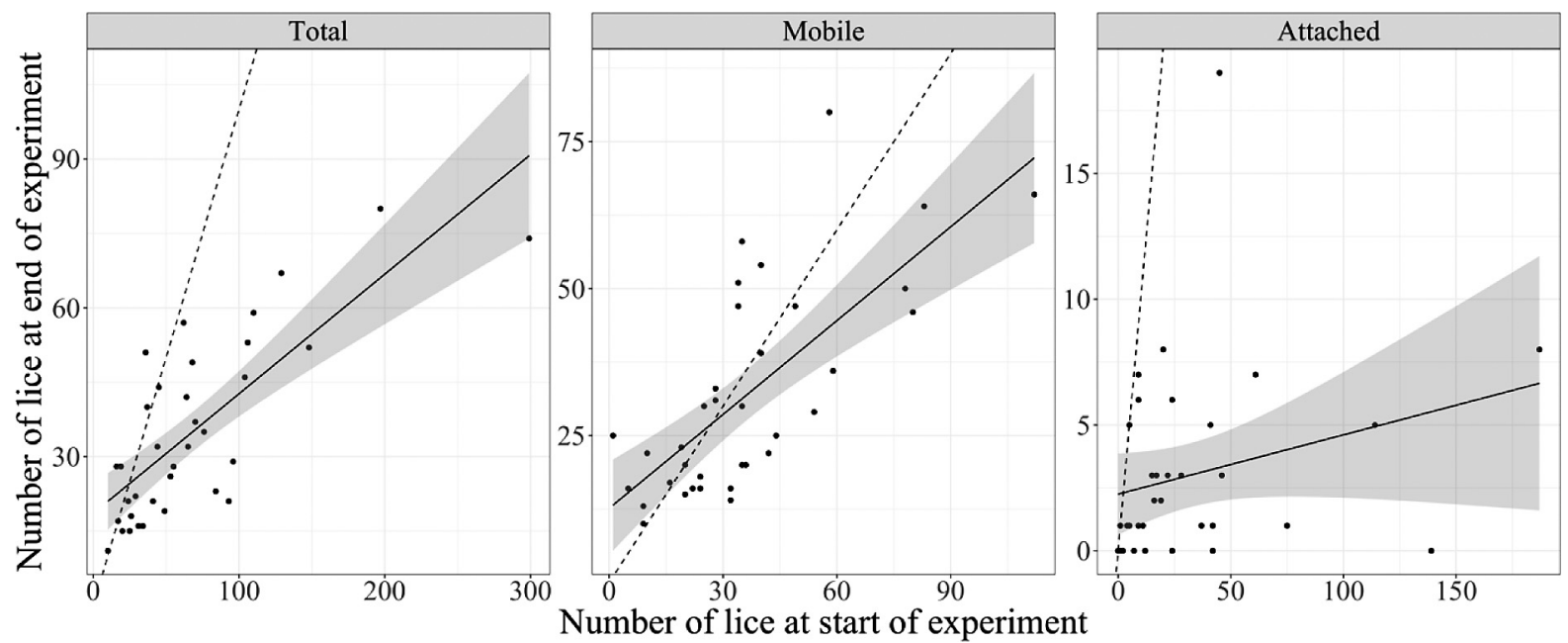

Fig. 6. Cross-plot of end-of-trial vs. start-of-trial louse abundance on Salmo trutta, for (a) all louse stages, (b) mobile louse stages, and (c) attached louse stages, fitted with a smoothing line (solid black line) and estimated confidence intervals (shaded grey). Dashed line represents 1:1 line (i.e. no change from start to end)

the effect of salinity on total and mobile lice, and the effect of temperature on attached lice is illustrated by residual plots.

\section{DISCUSSION}

\subsection{Main findings}

The aim of this study was to document how sea trout behave in a natural halocline when infested with salmon lice. Sea trout in this study had a narrow depth range, but responded to surface temperature, light intensity, and mobile stages of salmon lice, by swimming shallower with high temperatures, high abundances of mobile lice, and low light intensities. However, individual variation in depth preference was much larger than the effect of infestation levels, with some individuals choosing to stay at deeper depths (and more-saline water) even though they had a high number of lice. This individual preference has also been recognized for trout studied in their natural habitat (Kristensen et al. 2019).

The present study also aimed to investigate the potential change in lice abundance on sea trout when only allowed to displace vertically according to the conditions in a natural halocline. The number of lice on the sea trout generally decreased during the trials. After correcting for initial abundances of lice, it was clear that the presence of low-salinity surface water decreased the number of lice. As surface salinity explained this reduction better than the experienced salinity of the individual, it suggests that short exposure to very low salinities, rather than long-term 
Table 4. Analysis of end-of-trial louse abundance for all stages $\left(L_{i}^{\mathrm{TOT}}\right)$, mobile stages $\left(L_{i}^{\mathrm{MOB}}\right)$, and attached stages $\left(L_{i}^{\text {ATT }}\right)$. Top model from model selections $2 \mathrm{a}, 3$, and $4 \mathrm{a}$ (Table S2b), where $\beta_{0}$ is the intercept, $\bar{T}_{i}^{\text {EXP }}$ is averaged experienced temperature, $\bar{S}_{t}^{\text {up }}$ is averaged surface salinity $(0.2$ $\mathrm{m})$, and $W_{i}$ is mean mass of start and end sample. $i$ : variation in the factor across individuals; $t$ : variation across time; superscripted 1 (start) and 2 (end) denote time of sampling

\begin{tabular}{|lrr|}
\hline & Estimate & \multicolumn{1}{c|}{$\mathrm{p}$} \\
\hline Top model, $L_{i}^{\text {TOT2 }} \sim$ & \\
$\beta_{0}$ & -36.686 & 0.007 \\
$L_{i}^{\text {TOT1 }}$ & 0.223 & $<0.001$ \\
$\bar{S}_{t}^{\text {up }}$ & 3.345 & $<0.001$ \\
$W_{i}$ & 0.006 & 0.326 \\
Top model, $L_{i}^{\text {MOB2 }}$ & & \\
$\beta_{0}$ & -33.854 & 0.019 \\
$L_{i}^{\text {ATT1 }}$ & 0.142 & 0.015 \\
$L_{i}^{\text {MOB1 }}$ & 0.341 & $<0.001$ \\
$\bar{S}_{t}^{\text {up }}$ & 2.845 & 0.002 \\
$W_{i}$ & 0.007 & 0.310 \\
Top model, $L_{i}^{\text {ATT2 }}$ & & \\
$\beta_{0}$ & 25.295 & 0.001 \\
$L_{i}^{\text {ATT1 }}$ & 0.052 & 0.008 \\
$L_{i}^{\text {MOB1 }}$ & -0.046 & 0.136 \\
$\bar{T}_{i}^{\text {EXP }}$ & -1.660 & 0.004 \\
$W_{i}$ & -0.001 & 0.482 \\
\hline
\end{tabular}

exposure to moderate salinities, is the driving force behind the effect of haloclines on the decrease in lice numbers. Additionally, high temperature decreased the number of attached lice. Since temperature increases the developmental rate of sea lice (Stien et al. 2005), this effect is most likely a result of the increased moulting rate from attached to mobile stages during the trials.

The behaviour of the fish within the depth range of the net-pen used in the current study may not be entirely representative of real-life behaviour, where the fish inhabit a larger vertical realm. Nevertheless, our findings are reasonably consistent with those from earlier studies of fish in their natural habitat (Lyse et al. 1998, Rikardsen et al. 2007, Eldøy et al. 2017, Kristensen et al. 2018).

The fish that survived the trials showed deviating behaviour, resembling stress, the first $2 \mathrm{~d}$ after release in the net-pen. Rikardsen et al. (2007) also found that fish showed deviating behaviour in the period just after release. They explained this by the switch in habitat, from freshwater to saline, and individuals spending less than $2 \mathrm{~d}$ at sea before recapture were therefore removed from the analysis. Rikardsen et al. (2007) did not mention the potential effect of tagging, which is one of the hypothesized explanations for the deviating behaviour seen in the current study, the other being stress induced by the enclosure of the net-pen (confinement). Due to the lack of a control group, in both Rikardsen et al. (2007) and the current study, the ultimate cause cannot be settled with certainty. The same behaviour was recognized for an extended period of time for the fish that died during the trials. Kristensen et al. (2019), studying trout in their natural habitat, also found a difference in behaviour when comparing survivors of marine migration with non-survivors.

Light had a significant, albeit small effect, on vertical positioning of the sea trout. Light intensity is an important factor when studying depth preference, as light is the main limiting factor for vision, which most fish, including sea trout, are dependent on when locating food and avoiding predators (Bone \& Moore 2008). Good light conditions make for good foraging conditions, as food is easy to detect, both for the individual and for predators. Hence, fish face a trade-off between feeding and predator avoidance (Magnhagen et al. 2008). A common solution to this problem is to only occupy the shallow waters with high light intensities when feeding and relocate at greater depths the rest of the time to minimize the risk of being eaten (Magnhagen et al. 2008). This is the driving mechanism behind the behaviour known as diel vertical migration (DVM), which has been observed for sea trout in Rikardsen et al. (2007) and later confirmed by a more recent study by Eldøy et al. (2017). Even though data on light intensity was not collected at our study site, introducing a potential source of error, the DVM was seemingly prominent when looking at the raw data. Nevertheless, the model parameter of the top model only predicted a very small shift in vertical positioning when light changed throughout the day. Several factors could explain the lack of prominence of this pattern in the current top model, one being the individual variation. Also, the data on surface light intensity was log-transformed in the top model. The relevance of this was tested by fitting the same model with no log transformation of surface light. The difference in parameter estimates and AIC was minimal, and hence the log transformation was deemed trivial in this context. Another explanation could be the fact that the depth data was $\log$ transformed as well. This was our solution for dealing with the data being aggregated close to the surface and not having negative values, drawing on the methodological response to the same challenge in previous studies like Eldøy et al. (2017). This approach implies less emphasis on the extreme values in the data distribution, the values that seemed to be highly correlated with high surface light intensi- 
ties, and hence potentially remove the pattern from the data. The result was a model that seemingly did a poor job in predicting occurrences of sporadic dives into deep sections of the cage during the day. It therefore seems clear that sea trout vertical behaviour is affected by light, but not in a fashion that can be easily predicted by a linear model.

The top model did distinguish between the categories defined by the abundance of mobile lice, showing that more highly-infested individuals tended to stay closer to the surface. When looking at the observed data, the diving behaviour that was hypothesized to be a response to light was less prominent in the highly-infected individuals. Judging by the size of the parameter estimate, louse abundance seemed to be the best predictor of depth preference. This influence of lice on fish depth preference should be interpreted with caution, as several factors may weaken the pattern through the analysis, including individual variation and the lack of controls. Salmon lice are known to be the trigger of premature return to rivers during summer months (Birkeland 1996, Birkeland \& Jakobsen 1997). The phenomenon is interpreted as a behavioural adaptation strategy to accommodate the osmoregulatory stress caused by the salmon lice (Birkeland 1996, Birkeland \& Jakobsen 1997, Wells et al. 2007). As there was a strong correlation between salinity and depth, with salinities increasing with depth, the active use of freshwater refuge at the surface could be the underlying cause for the negative relationship between depth and abundance of mobile lice.

Surface salinity proved a better predictor for reduction in lice rather than estimated experienced salinity throughout the study period. This suggests that short-term exposure to low salinities, rather than long-term exposure to moderate salinities, is the driving force behind the salinity-driven reduction in lice. Consequently, sea trout can adaptively affect their parasite abundance by staying in the surface layer. Earlier findings on the specific freshwater tolerance of salmon lice are rather conflicting. Finstad et al. (1995) found that lice could survive on fish for up to $3 \mathrm{wk}$ in freshwater, with no significant difference between stages, while Wright et al. (2016) found that smaller attached stages died after only $2 \mathrm{~h}$ of freshwater exposure, while larger attached stages could survive for up to $8 \mathrm{~d}$. This might reflect the difference in tolerance based on what species the lice are attached to, as Finstad et al. (1995) studied Arctic charr Salvelinus alpinus, while Wright et al. (2016) carried out the experiment with Atlantic salmon Salmo salar. Similar experiments with sea trout $S$. trutta are yet to be done. In contrast to our study, both of the above-mentioned were done in 0 ppt salinity. On the other hand, Bricknell et al. (2006) carried out similar experiments using environmental salinity concentrations. They found that both survival and host infectivity of salmon lice was greatly compromised by exposure to reduced salinity, which could be supported by our findings. The results of our study also coincide with earlier studies where fish caught in the inner part of fjord systems, with high freshwater impact, were found to have less lice than fish caught further out (Helland et al. 2015). Staying in the surface layer represents an increased risk of predation and loss of foraging opportunity, so this risk must be outweighed by the gain of reducing louse abundance and counteracting osmoregulatory stress or imbalance (Birkeland 1996). All sea trout in the study had lice and this may therefore explain the inclusion of surface salinity in the top model for depth selection.

Highly-infested sea trout had a shallower depth preference compared to sea trout with lower infestation levels. Mobile louse abundance was a better predictor of depth preference than the total abundance of all louse stages. The epidemiology of salmon lice could explain this. Osmotic and ionic imbalance in the form of an increase in plasma chloride levels, caused by lesions in the skin, has been observed when lice reach the chalimus stage (Bjørn \& Finstad 1997). However, these effects are more dramatic when lice reach the preadult and adult life stages (Bjørn \& Finstad 1997, Wells et al. 2006, 2007), which also marks a dramatic increase in virulence. The abundance of lice is also found to be positively correlated with the severity of osmoregulatory stress in the fish, indicated by a rise in plasma chloride levels (Bjørn \& Finstad 1997). Hence, it is in line with earlier findings that mobile louse stages possibly have a more substantial impact on the fish than attached louse stages. However, there are limitations that have to be taken into account when interpreting the results, including the lack of an uninfected group of controls. As we were dependent on the use of wildcaught fish for this study, this option was ruled out, as we did not succeed in catching any uninfected fish during the timespan of the study.

An interaction between surface salinity and mobile louse abundance might be expected, because surface salinity should have a larger impact on depth preference of individual fish with high abundances of lice. However, although the fresher water at the surface may reduce the impact of lice, there is also a cost to being surface-oriented (Magnhagen et al. 2008). This creates a classic behavioural trade-off 
that each individual has to face as the severity of lice infestations increase. In our study, the model without the interactions outperformed the one including interactions. Hence, the study failed to support the presence of any interactions. Limitations of the study design, such as small samples of individuals with low lice values, and uneven (overdispersed) lice abundance, could affect the ability to detect interactions in the data. Also, the effect of tagging as an osmoregulatory stressor, and hence the cause of the relationship between depth preference and surface salinity, could not be ruled out due to the lack of control fish without tags. This is the nature of any tagging study, as there are great challenges related to obtaining data without the use of tags. Even so, the results suggest that the effect of lice was generally that fish swam in shallower depths regardless of the degree of surface salinity, and that they swam shallower when surface salinity was lower regardless of lice intensity.

Sea trout was found closer to the surface as temperature increased in our study. Temperature can have a large effect on physiological processes in animals, including fish. There have been several studies on the preferred temperature of trout, and the results are not unequivocal. While Larsson (2005) reported a thermal preference of $16^{\circ} \mathrm{C}$, Reynolds \& Casterlin (1979) landed on a considerably lower temperature of $12.2^{\circ} \mathrm{C}$. Larsson pinpoints the difference in feeding regime as a possible reason for the conflicting results, as the fish in the study of Reynolds \& Casterlin (1979) study were not fed, in contrast to Larsson (2005). Rikardsen et al. (2007) found that fish stayed deeper throughout the summer, as the temperatures increased. Their finding also included sea trout experiencing higher temperatures throughout the season, hence not adequately compensating for increased temperatures with vertical displacement. Their statistical analyses included 2-sample $t$-tests on the data averaged on the individual. Hence, they did not test for a relationship between depth use and temperature. Nevertheless, based on their reported results, if there is a relationship, it is likely positive, which conflicts with the findings in the current study. This could possibly be explained by the vast individual variance, pointed out earlier, as the fish in the first trial may have had a natural preference for staying deeper, and the temperature just happened to be very low during this time period.

High temperature also led to a decrease in the number of attached stages at the end of the experiment. This is most likely explained by recruitment into mobile stages, as the rate of development is highly dependent on temperature (Pike \& Wadsworth 1999).
However, total lice abundance decreased, so a higher mortality rate may also have contributed. The effect of high temperatures on the mortality of salmon lice is not well documented. It has been observed that the parasite was absent from Norwegian salmon farms when water temperature was higher than $18^{\circ} \mathrm{C}$ (Boxaspen 2006). The maximum measured temperature in the surface during the current study was $17.5^{\circ} \mathrm{C}$, and $10 \%$ of the surface temperature values were over $15^{\circ} \mathrm{C}$. This is quite high and could be a possible explanation for the relationship.

Another interesting finding, which has to be treated with caution, was the inclusion of mobile lice with a negative parameter estimate in the top model for the end-of-trial abundance of attached stages. This could indicate that mobile lice actively remove attached stages from the fish. The hypothesis has been brought up before (Jakobsen \& Gabrielsen 2003). They found reduced chalimus abundance on experimentally challenged fish when adult female lice were present. The mechanisms behind this are not known, but adult lice may benefit by prolonging host survival and therefore indirectly increase their own lifetime reproductive success (Jakobsen \& Gabrielsen 2003).

Eldøy et al. (2017) found a relationship between depth preference and size of the fish, measured by length. Size does matter in relation to antipredator strategies, as a smaller body makes for an easier prey, hence increasing the cost of staying in shallow and risky waters. When choosing fish for this study, we aimed for a minimum variation in fish size, in order to reduce deviation in baseline behaviour. However, due to limited catches, fish of variable size had to be included in the study. Therefore, length was also included in the global model for swimming depth, although it was excluded during the model selection. This could indicate that the selectivity for size was sufficient, as the individual variation was accounted for as a random effect.

\subsection{Implications for the future}

Currently, data originating from monitoring programmes are used in the status assessment of one of the most critical obstacles to the Norwegian government's ambition for a 5-fold increase in annual output of the aquaculture industry (Agnalt et al. 2017, Guttormsen 2017). Results from the current study suggest more emphasis needs to be put on the importance of individual variation in this context, as not addressing it or underestimating its significance has 
the potential of introducing a considerable source of error concerning the question of representation.

The role of sea trout in the new monitoring system is still uncertain, as knowledge around how populations respond to salmon lice is still limited. The current study presents strong indications that salmon lice have an impact on the individual depth preference of trout, which in turn has an effect on louse abundances. This suggests that fish, to some degree, were able to compensate for the cost of salmon lice through this fine-scale change in vertical behaviour when the conditions were right. Assuming this is correct, it would be relatively easy to implement, as it suggests that the potential for compensation in a system is mostly dependent on the availability of low-salinity surface water. Due to the unexpectedly high mortality rate during the trials, more research effort is needed for validation of the findings of the current study.

Based on the findings of the current study, caution is advised when treating data that originate from the first days after tagging, as the behaviour during those days was found to be deviating from the rest. More emphasis should be put on developing a good protocol for treating spatial and temporal behavioural data, and making the link to associated environmental factors, to make for consistency in statistical analysis and easier comparison and interpretation of results. To our knowledge, this was also the first study on marine behaviour of sea trout that addressed autocorrelation, despite the presence of published work on studies based on the same type of data (Rikardsen et al. 2007, Eldøy et al. 2017, Halttunen et al. 2017). Accounting for autocorrelation is strongly encouraged, as doing so significantly reduced the patterns in the data, suggesting an overparameterization of models trying to predict reality, inflated p-values, and hence increased likelihood of a type II error when neglecting it.

\subsection{Conclusion}

The current study was the first telemetry study on the marine behaviour of wild sea trout in a semienclosed system. This approach could function as an alternative for pilot studies and for testing hypotheses that need high-frequency data resolution, as the results on general behaviour coincided well with findings from studies on sea trout in the wild. The results support previous knowledge on vertical diurnal behaviour, enlighten the role of salmon lice in optimal vertical positioning, and raise the issue of the implications of temperature and salinity preference.
Further, results suggest that sea trout has the potential to compensate for the cost of salmon lice through changes in vertical behaviour that is directly linked to surface salinity.

Acknowledgements. Thanks to Shad Mahlum for advice and proofreading of an earlier version of the manuscript. Also, thanks to Eirik Straume Normann and Bjørnar Skår for designing and building the net-pen installation used in the study. Finally, thanks to Børge Merkesvik for all the help during fieldwork and inspirational conversations. This study was financed in combination by the Norwegian Research Council (proj. no. 243912/E50) and the Norwegian Environment Agency.

\section{LITERATURE CITED}

Agnalt AL, Albretsen J, Asplin L, Bannister R and others (2017) Risikorapport norsk fiskeoppdrett 2017. Fisken Havet no. 2-2017. Institute of Marine Research, Bergen

Barlaup BT, Gabrielsen SE, Løyland J, Schläppy ML, Wiers T, Vollset KW, Pulg U (2013) Trap design for catching fish unharmed and the implications for estimates of sea lice (Lepeophtheirus salmonis) on anadromous brown trout (Salmo trutta). Fish Res 139:43-46

Bartoń K (2018) MuMIn: multi-model inference. R package version 1.40.4. https://cran.r-project.org/package=MuMIn

Birkeland K (1996) Consequences of premature return by sea trout (Salmo trutta) infested with the salmon louse (Lepeophtheirus salmonis Krøyer): migration, growth, and mortality. Can J Fish Aquat Sci 53:2808-2813

Birkeland K, Jakobsen PJ (1997) Salmon lice, Lepeophtheirus salmonis, infestation as a causal agent of premature return to rivers and estuaries by sea trout, Salmo trutta, juveniles. Environ Biol Fishes 49:129-137

Bjørn PA, Finstad B (1997) The physiological effects of salmon lice infection on sea trout post smolts. Nord J Freshw Res 73:60-72

Bone Q, Moore RH (2008) Biology of fishes. Taylor \& Francis, New York, NY

Boxaspen K (2006) A review of the biology and genetics of sea lice. ICES J Mar Sci 63:1304-1316

* Bricknell IR, Dalesman SJ, O'Shea B, Pert CC, Luntz AJM (2006) Effect of environmental salinity on sea lice Lepeophtheirus salmonis settlement success. Dis Aquat Org 71: 201-212

Burnham KP, Anderson DR (2002) Model selection and multimodel inference: a practical information-theoretic approach. Springer-Verlag, New York, NY

Eldøy SH, Davidsen JG, Thorstad EB, Whoriskey FG and others (2017) Marine depth use of sea trout Salmo trutta in fjord areas of central Norway. J Fish Biol 91:1268-1283

Finstad B, Bjørn PA, Nilsen S (1995) Survival of salmon lice, Lepeophtheirus salmonis Krøyer, on Arctic charr, Salvelinus alpinus (L.), in fresh water. Aquacult Res 26: 791-795

Forseth T, Finstad B, Thorstad EB (2012) Lakselus og effekter på vill laksefisk - fra individuell respons til bestandseffekter. Temarapport dra Vitenskapelig råd for lakseforvaltning 3. http://hdl.handle.net/11250/2392402

Gałecki A, Burzykowski T (2013) Linear mixed-effects models using R: a step-by-step approach. Springer, New York, NY 
Guttormsen A (2017) Forutsigbar og miljømessig bærekraftig vekst i norsk lakse- og ørretoppdrett. Meld St 16, Kunnskapsdepartementet, Oslo

Halttunen E, Gjelland KØ, Hamel S, Serra-Llinares RM and others (2017) Sea trout adapt their migratory behaviour in response to high salmon lice concentrations. J Fish Dis 41:953-967

Helland IP, Uglem I, Jansen PA, Diserud OH, Bjørn PA, Finstad B (2015) Statistical and ecological challenges of monitoring parasitic salmon lice infestations in wild salmonid fish stocks. Aquacult Environ Interact 7:267-280

Jakobsen P, Gabrielsen SE (2003) Interactions between adult and juvenile salmon lice on their hosts reduce their virulence. In: Proc XXI Symp Scand Soc Parasitol. Bull Scand Soc Parasitol 12-13:15-16

Kristensen ML, Righton D, del Villar-Guerra D, Baktoft H, Aarestrup K (2018) Temperature and depth preferences of adult sea trout Salmo trutta during the marine migration phase. Mar Ecol Prog Ser 599:209-224

Kristensen ML, Righton D, del Villar-Guerra D, Baktoft H, Aarestrup K (2019) Behaviour of adult sea trout Salmo trutta that survive or die at sea. Estuar Coast Shelf Sci 227:106310

* Larsson S (2005) Thermal preference of Arctic charr, Salvelinus alpinus, and brown trout, Salmo truttaimplications for their niche segregation. Environ Biol Fishes 73:89-96

Liu Y, Olaussen JO, Skonhoft A (2011) Wild and farmed salmon in Norway - a review. Mar Policy 35:413-418

Lyse AA, Stefansson SO, Fernö A (1998) Behaviour and diet of sea trout post-smolts in a Norwegian fjord system. J Fish Biol 52:923-936

Magnhagen C, Braithwaite VA, Forsgren E, Kapoor BG (2008) Fish behaviour. Science Publishers, Enfield, NH

Pike AW, Wadsworth SL (1999) Sealice on salmonids: their biology and control. Adv Parasitol 44:233-337

R Core Team (2014) R: a language and environment for statistical computing. R Foundation for Statistical Computing, Vienna

Reynolds W, Casterlin M (1979) Thermoregulatory behavior of brown trout, Salmo trutta. Int J Aquat Sci 62:79-80

Rikardsen AH, Diserud OH, Elliott JM, Dempson JB, Sturlaugsson J, Jensen AJ (2007) The marine temperature and depth preferences of Arctic charr (Salvelinus alpinus) and sea trout (Salmo trutta), as recorded by data

Editorial responsibility: Bengt Finstad, Trondheim, Norway storage tags. Fish Oceanogr 16:436-447

* Serra-Llinares RM, Bøhn T, Karlsen Ø, Nilsen R and others (2020) Impacts of salmon lice on mortality, marine migration distance and premature return in sea trout. Mar Ecol Prog Ser 635:151-168

Soetaert K, Petzoldt T, Meysman F (2016) marelac: tools for aquatic sciences. R package version 2.1.6. https://cran.rproject.org/package $=$ marelac

Stien A, Bjørn PA, Heuch PA, Elston DA (2005) Population dynamics of salmon lice Lepeophtheirus salmonis on Atlantic salmon and sea trout. Mar Ecol Prog Ser 290: 263-275

Taranger GL, Karlsen Ø, Bannister RJ, Glover KA and others (2015) Risk assessment of the environmental impact of Norwegian Atlantic salmon farming. ICES J Mar Sci 72: 997-1021

* Thorstad E, Todd CD, Uglem I, Bjorn PA and others (2015) Effects of salmon lice Lepeophtheirus salmonis on wild sea trout Salmo trutta - a literature review. Aquacult Environ Interact 7:91-113

Thorstad E, Todd C, Uglem I, Bjørn P and others (2016) Marine life of the sea trout. Mar Biol 163:47

Vollset KW, Dohoo I, Karlsen Ø, Halttunen E and others (2017a) Disentangling the role of sea lice on the marine survival of Atlantic salmon. ICES J Mar Sci 75:50-60

Vollset KW, Halttunen E, Finstad B, Karlsen Ø, Bjørn PA, Dohoo I, Gibbs M (2017b) Salmon lice infestations on sea trout predicts infestations on migrating salmon postsmolts. ICES J Mar Sci 74:2354-2363

*Wells A, Grierson CE, MacKenzie M, Russon IJ and others (2006) Physiological effects of simultaneous, abrupt seawater entry and sea lice (Lepeophtheirus salmonis) infestation of wild, sea-run brown trout (Salmo trutta) smolts. Can J Fish Aquat Sci 63:2809-2821

*Wells A, Grierson CE, Marshall L, MacKenzie M and others (2007) Physiological consequences of premature freshwater return for wild sea-run brown trout (Salmo trutta) postsmolts infested with sea lice (Lepeophtheirus salmonis). Can J Fish Aquat Sci 64:1360-1369

WWright DW, Oppedal F, Dempster T (2016) Early-stage sea lice recruits on Atlantic salmon are freshwater sensitive. J Fish Dis 39:1179-1186

Zuur A, Ieno EN, Walker N, Saveliev AA, Smith GM (2009) Mixed effects models and extensions in ecology with R. Springer, New York, NY

Submitted: September 12, 2019; Accepted: March 25, 2020 Proofs received from author(s): May 13, 2020 